\title{
Hunting activity by urban Peregrine Falcons (Falco peregrinus) during autumn and winter in south-west Norway
}

\author{
Bjarne Emil Time
}

Loen 1, HO 402, NO-4340 Bryne, Norway; e-mail: bjarneemil@hotmail.com

\begin{abstract}
In 2015/16 a pair of Peregrine Falcons Falco peregrinus frequented a $66 \mathrm{~m}$ high office building in a small town in south-west Norway. Using IR-flash cameras 61 days in the autumn and winter, day and night, the time of landings on the balcony cornices were recorded exactly. In total 93 hunting sorties were recorded, a majority of which took place around dawn and dusk. No less than $17 \%$ of the hunts occurred in the dark, between dusk and dawn. In autumn, waders and thrushes made up a substantial part of their diet. During winter many corvids rest in a park near the building, and at that time the Peregrines mostly fed on Jackdaws Corvus monedula, killed by the female in coordinated hunting. Often the male landed on the cornice without prey, to eat leftovers. Artificial light probably enabled the falcons to hunt at night.
\end{abstract}

Key words: Peregrine Falcon; nocturnal hunting; urban raptor ecology; non-breeding biology; artificial light

\section{INTRODUCTION}

The Peregrine Falcon Falco peregrinus is probably one of the most studied birds of prey in the world. Especially their hunting technique and prey (mostly birds), are well documented. Nearly all studies are from their natural nesting habitats, like steep cliffs, often close to water and open landscape.

The pair normally separate at the end of the summer (White et al. 2002). Scandinavian Peregrines migrate to the British Isles or south to the European continent, but if they find enough food late in the year, they will stay, as in Rogaland, a county in the south-west of Norway, where a large population of Peregrines is located (about 190 pairs; Steen 2008).

Peregrine Falcons use all types of high constructions as resting or spotting sites. From here, they start hunting, and frequently return with prey to eat or to keep for later (Unwin 2008).

Generally, Peregrine Falcons chase and kill birds from sunset until dusk, but in some large cities they are reported to be hunting in the dark, close to high illuminated buildings (DeCandido \& Allen 2006). Many of those are offices, with no or limited admittance for the public, and of course, in the dark it is difficult to study all of the hunting activity of the falcons.

A pair of Peregrine Falcons has frequented a tall building in Rogaland, SW Norway, every autumn and winter since 2013. In 2015 and 2016, I got admittance to this building, and the opportunity, for the first time in Norway, to record the exact time of landings with prey day and night.

\section{MATERIAL AND METHODS}

Bryne is a small town surrounded by farmland, in the region of Jæren, Rogaland (Figure 1).There is only one high building (called Høghuset) in the town, and this is the building used by the falcons. A view from the building is shown in Figure 2. Høghuset is 66 $\mathrm{m}$ high, and has 19 floors. It is located $450 \mathrm{~m}$ from Frøylandsvatnet, a freshwater lake, and Sandtangen, a park/small forest. The wetland is important for many bird species, especially waders and ducks. The water flows like a small river through the centre of the town. The building has three sheltered balconies with cornices. The falcons used only the balconies of the 13th and 15th floor. The cornices are $34 \mathrm{~cm}$ broad, and the total length is about $150 \mathrm{~m}$.

To document the activity of the falcons on Høghuset, I used one web-camera (D-Link/DCS $7110 \mathrm{HD}$ ), fixed to one position on 13th floor, and a DSLR-camera (Nikon D3s) with a $600 \mathrm{~mm}$ lens (Nikon 1:4 G ED), to film hunting scenes. In addition, I used three digital scouting cameras (Wildgame/Cloak 6 and Cuddeback/ Long Range IR). They have IR-flash and passive IR motion sensor and take still pictures day and night. My report is an analysis of photo and video sequences lasting for $1 \mathrm{~min}$ or more. The cameras operated from 15 October 2015 to 23 March 2016.

Because of high activity by the falcons in October and November, I used the scouting cameras alternately on the 13th or 15th balcony.

In December, and the next two months, the falcons confined their plucking and eating to only one site, a 


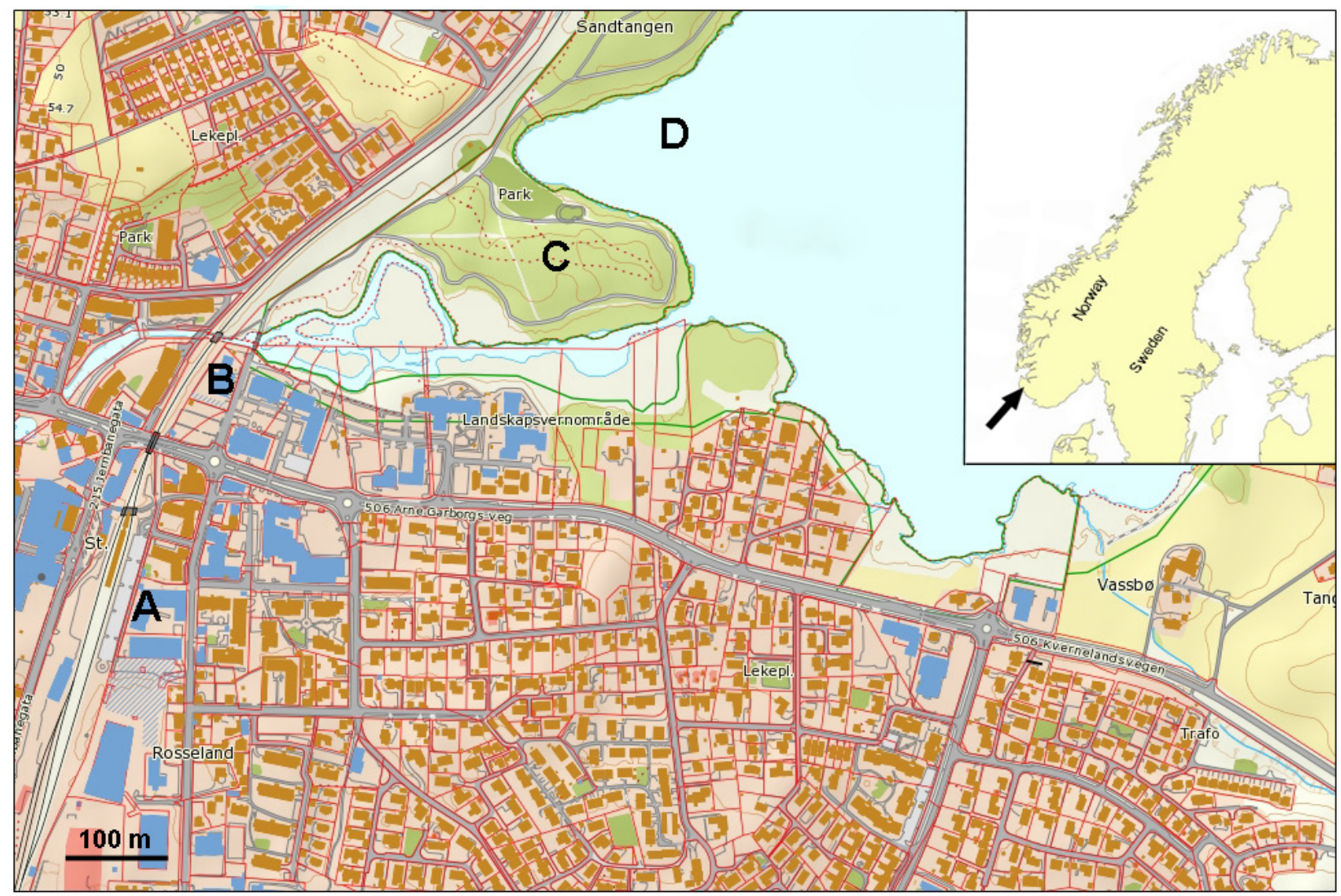

Figure 1. The centre of Bryne. $\mathrm{A}=$ Høghuset, $\mathrm{B}=$ Mast, $\mathrm{C}=$ Sandtangen park, $\mathrm{D}=$ Lake Frøylandsvatnet. The location of Bryne is marked with arrow on inserted map.

small part of the balcony cornice (about $6 \mathrm{~m}$ long) on the 13th floor, facing east. I mounted the cameras 2 $\mathrm{m}$ apart to get the best pictures and the possibility to identify the sexes.

This autumn and winter, the park Sandtangen (Figure 1) was an important resting place for corvids at night. On 19th November 2015, about 1500 Hooded
Crows Corvus cornix and 500-800 Jackdaws Corvus monedula stayed in the park, (Øyvind Gjerde personal communication.).

The weather on Jæren in October to December was rainy and the temperature above normal. January became colder, with snow and temperature below zero for many days, before the weather improved.

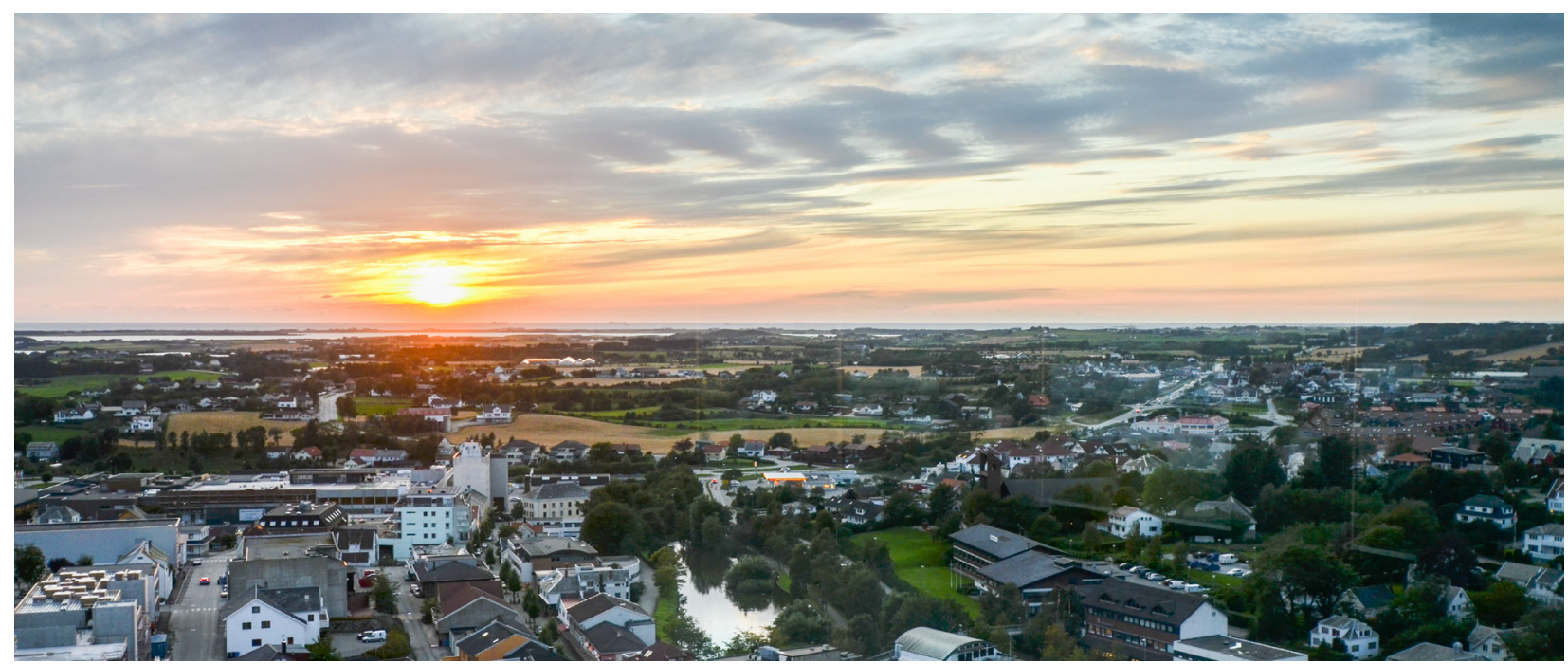

Figure 2. The view from the 19th floor of Høghuset, facing west. 


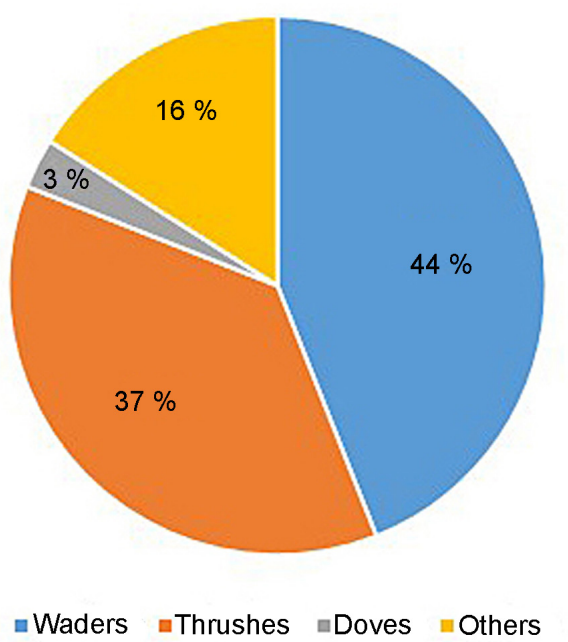

Figure 3. Diet composition of Peregrine Falcons in Bryne, Rogaland, October and November $2015(\mathrm{n}=32)$.

\section{RESULTS}

In the period of October to the end of November, I collected 32 prey items (whole bodies, or fragments of birds) brought to the two balconies by the falcons. Waders dominated the sample (44\%), and Eurasian Woodcock Scolopax rusticola formed the majority (Figure 3), but also many thrushes Turdus spp. were brought in (37\%). Doves (Columbidae), a main prey for many urban Peregrine Falcons, were rare in the sample (3\%). Details are given in Appendix 1.

The falcons normally used the west front of Høghuset to rest or wait for prey, sitting alone or together as a pair, the latter in $24 \%$ (8 of 33) of the observations from October to December, and in $45 \%$ (15 of 33) of the observations from December to March (Figure 4).

A total of 93 landings in 61 days and nights, were recorded on Høghuset, $45 \%$ with prey. Sixteen (17\%) of the landings occurred at night, of which $10(62 \%)$ were with prey (Figure 5). Very late night or early morning landings with prey (Eurasian Woodcock) occurred on

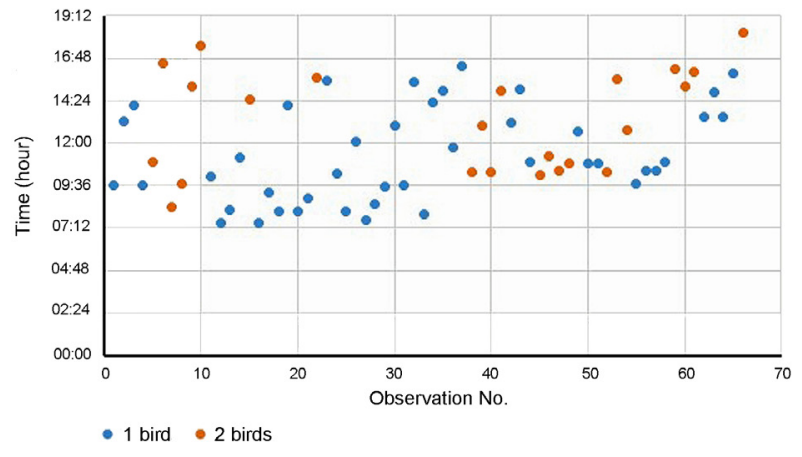

Figure 4. 66 observations of the Peregrine Falcons resting on the west front of Høghuset, alone or as a pair. October: 1-10. November: 11-33. December: 34-44. January: 45-57. February: 58-62. March: 63-66.

28 October $(0327 \mathrm{~h}), 17$ November $(0450 \mathrm{~h})$ and 15 March (0215 h) (Figure 6).

During the period from October to the end of November the cameras operated in all 11 days and nights, and documented 14 landings, of which only $28 \%$ were with prey. Ten of the landings were at night, and it was not possible to record the sex.

At the end of November, the falcons changed their behaviour. In addition to Høghuset they used a $43 \mathrm{~m}$ high telecommunication mast near Sandtangen. This part of the town has a big car park, well illuminated at night. The next two months (December and January), I spotted the Peregrines on the mast, totally 20 times in 17 days, between sunrise and late evening. I never observed two falcons on the mast at the same time. In 50 days and nights from December to March, Jackdaws were the main prey $(76 \%, \mathrm{n}=37)$. The falcons also killed some doves, thrushes and Eurasian Woodcocks.

In December (15 days and nights), the female landed 11 times, and always at dusk, between 1622 $\mathrm{h}$ and $1851 \mathrm{~h}$, in 10 of the landings (91\%) with prey. During the same month, the male landed 16 times, eight times between $0917 \mathrm{~h}$ and $1654 \mathrm{~h}$, seven times (43\%) bringing prey (Blackbird Turdus merula or Common

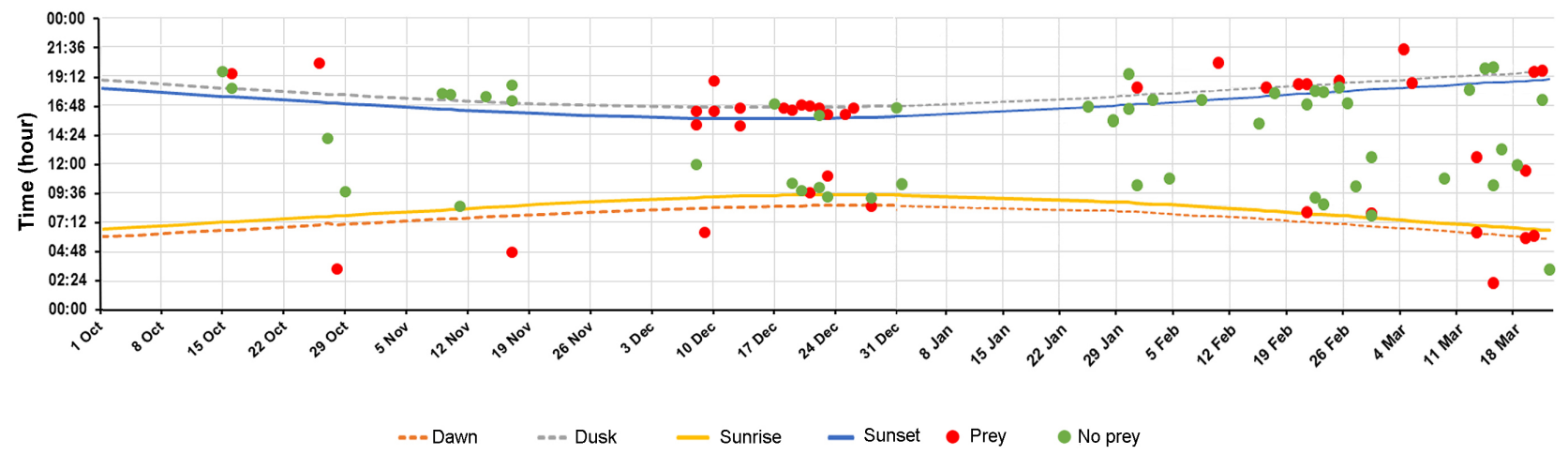

Figure 5. Landings $(n=93)$ by Peregrine Falcons on Høghuset with or wihout prey, from 15 October 2015 to 23 March 2016. 


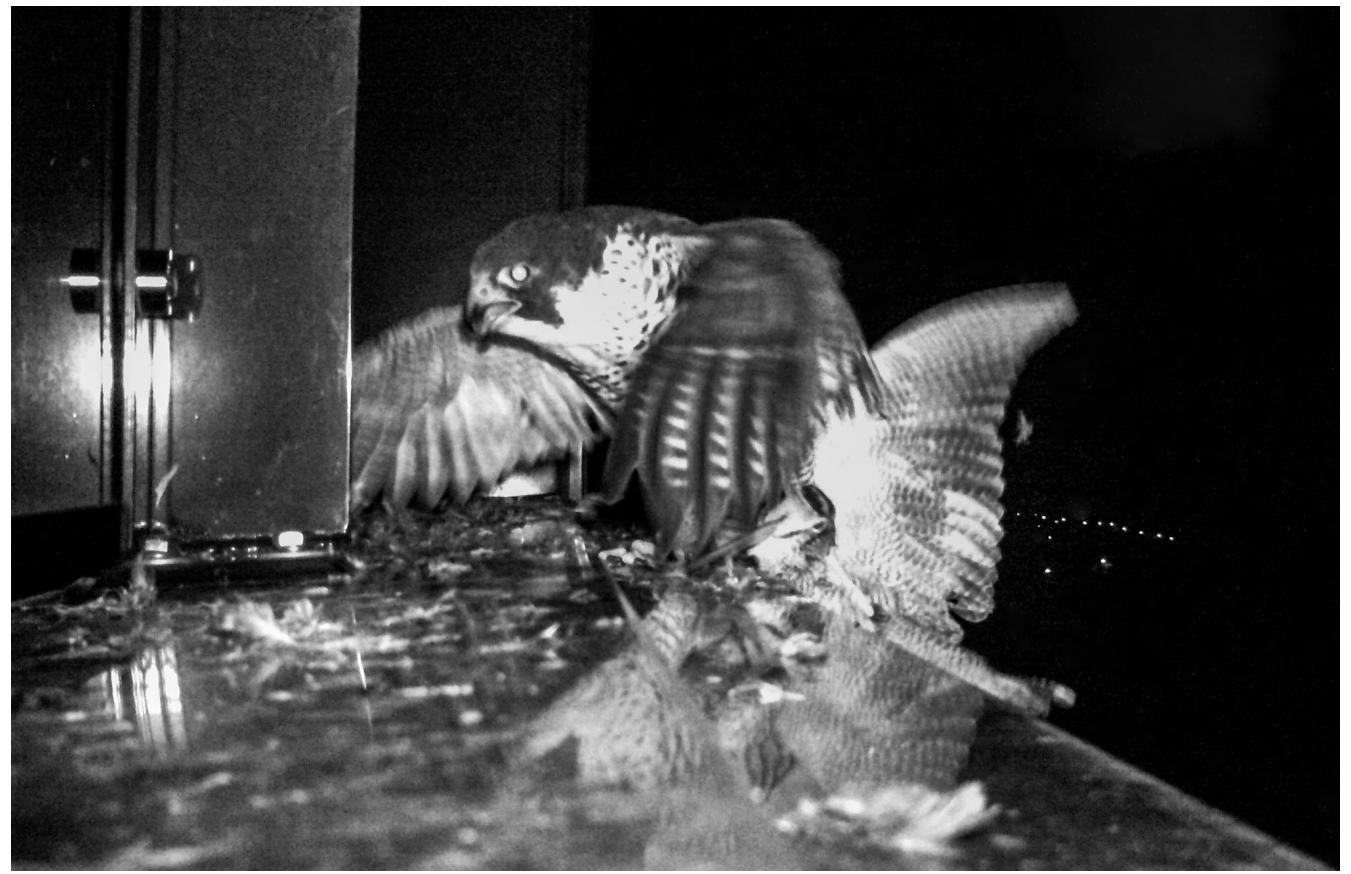

Figure 6. A Peregrine Falcon landing at night on Høghuset with a Eurasian Woodcock.

Snipe Gallinago gallinago), but never Jackdaw (Figure 7).

During January-March the female landed 34 times ( 35 days and nights) and $44 \%$ of the landings were between $0750 \mathrm{~h}$ and $1811 \mathrm{~h}$. In $17(50 \%)$ of the

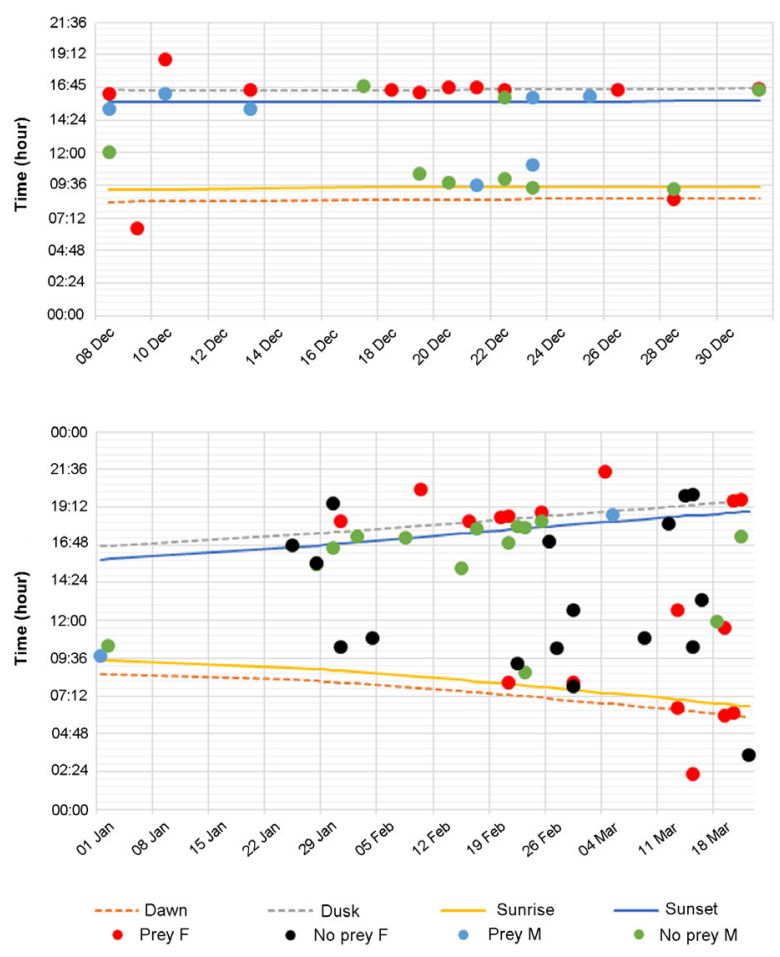

Figure 7. Landings $(n=78)$ by the Peregine male $(M)$ and female (F) at 13th floor of Høghuset with or without prey, from 8 Descember 2015 to 23 March 2016. landings, she brought prey. Thirteen (76\%) of these were at night (Fig 7, lower panel). In the same period the male landed 15 times on the cornice, eight (53\%) of which were in the daytime between $0947 \mathrm{~h}$ and $1636 \mathrm{~h}$, and only twice with prey.

\section{DISCUSSION}

The Peregrine Falcon is known to be active during the day, but hunts mostly in the morning and in the evening (Ratcliffe 1980). My study shows that the species hunts both in daylight and at night, but prefers the dusk and dawn. The results, based on exact time of landings, indicate that hunting at night is more common than expected from a bird of prey depending on the eyesight for hunting.

At night, the street light and the light from the buildings illuminate the study area. Most likely, the influence of the artificial light made it possible for the falcons to hunt at night. Cases of night-time hunting by Peregrine Falcons have been observed in urban areas in Europe as well as in North America, and artificial light is supposed to have facilitated such hunts (Rejt 2001, Kettel et al. 2016).

Hiding in the shadows of the light, probably gives the falcons a great benefit when attacking. Also the prey is more visible when the background is lit up (Cade \& Bird 1990), as the Eurasian Woodcocks have a bright front, and the Jackdaws' metallic feathers reflect the light.

After the nesting season, the pair split for some time, but may remain in the territory. as in Bryne. As 
a pair, they are able to hunt more efficiently and with greater success (Ratcliffe 2010).

Late in autumn, the falcons used both a mast and Høghuset as a spotting site. By using the mast, the predators gained an advantage compared to the prey, as hunting distance was reduced considerably. The prey of the Peregrine Falcons in the autumn until December included many different passerines and waders. The prey at this time were mainly migrants (thrushes and waders) leaving the region and therefore not accessible in wintertime (Hoodless \& Coulson 1994). Instead, the falcons started to hunt Jackdaws, not doves, as they normally do at other places. During the study, I observed few doves, so it is probable that they left the centre of Bryne to avoid the falcons.

Both Hooded Crows and Jackdaws roost numerously in the Sandtangen park, but crows were not in the sample of prey. The difference in weight between Jackdaw and crow could be an explanation. The falcons definitely kill smaller birds more easily (Thiollay 1982). My study yielded a limited sample of prey, but it corresponds very well to other studies (Rejt 2001).

When hunting large prey, the falcon will let the prey fall down to the ground, and may eat it there. A Jackdaw is half the weight of a crow and because of this, the falcons probably could bring it to Høghuset without spending too much energy. The Peregrine Falcon has reverse sexual dimorphism. The female is larger, and in general hunts larger birds than the male. In Bryne the female most likely killed all the Jackdaws brought to the balcony. On the ground beneath the mast, I found leftovers of thrushes and snipes, probably killed and eaten by the male.

The explanation as to why the male returned several times $(71 \%)$ to Høghuset empty-handed, could depend on the coordinated hunting. After catching the prey, the female normally eats first, regardless of who killed it. The male probably arrived later to eat the leftovers from the female's meals.

This study shows that advanced methods can be used, and are needed, to reveal the hunting strategies of birds of prey at night when they occur in urban areas with floodlight.

Acknowledgements. I would like to thank Vidar Selås and Torgeir Nygård for comments on the draft, Ingvar Byrkjedal for inspiration and help with the manuscript, and Harald Fjogstad for video and technical support. I am also grateful to Ann-Cathrin Hatlestad, Jane Dance and Geoffrey Acklam for improving the English.

\section{REFERENCES}

Cade, T.J. \& Bird D.M. 1990. Peregrine Falcons, Falco peregrinus, nesting in an urban environment: a review. Canadian Field Naturalist 104: 200-218.

DeCandido, R. \& Allen, D. 2006. Nocturnal hunting by Peregrine Falcons at Empire State Building, New York City. Wilson Journal of Ornithology 118: 53-58.

Haftorn, S. 1971. Norges fugler. Universitetsforlaget, Oslo.

Hoodless, A. N, \& Coulson J.C. 1994. Survival rates and movements of British and continental Woodcock, Scolopax rusticola, in the British Isles. Bird Study 41: 48-60.

Kettel, E.F., Gentle, L.K. \& Yarnell, R.W. 2016. Evidence of an urban Peregrine Falcon (Falco peregrinus) feeding young at night. Journal of Raptor Research 50: 321-323.

Ratcliffe, D. 1980. The Peregrine Falcon. Buteo Books, Vermillion, SD.

Ratcliffe, D. 2010. The Peregrine Falcon. T \& AD Poyser, London.

Rejt, L. 2001. Feeding activity and sesonal changes in prey composition of urban Peregine Falcon, Falco peregrinus. Acta Ornithologica 36: 165-169.

Steen, O.F. 2008. Vandrefalkens reetablering på Sør- og Østlandet. Bestand og ungeproduksjon i 2006. Vår Fuglefauna 31: 54-60.

Thiollay, J. M. 1982. Les ressources alimentaires, facteur limitant la reproduction d une population insulaire de faucons pelerius, Falco peregrinus brookei. Alauda 50: $1-44$.

Unwin, B. 2008. Peregrine Falcon adapting to urban lifestyle. The Telegraph, 06 Feb 2008.

White, C.M., Clum, N.J, Cade, T.J. \& Hunt, W.G. 2002. Peregrine Falcon (Falco peregrinus), The Birds of North America (P. G. Rodewald, ed.). Cornell Lab of Ornithology, Ithaca.

Received 26 July 2016. Accepted 14 November 2016 
Appendix 1. Birds killed by the Peregrine Falcons, from 18 August to 23 November 2015. Weights are maximum values, from Haftorn (1971).

\begin{tabular}{lcc} 
Prey & Number & Weight (g) \\
\hline Common Teal Anas crecca & 1 & 440 \\
Wood Pigeon Columba palumbus & 1 & 600 \\
European Golden Plover Pluvialis apricaria & 2 & 185 \\
Eurasian Woodcock Scolopax rusticola & 8 & 376 \\
Common Snipe Gallinago gallinago & 2 & 172 \\
Red Knot Calidris canutus & 1 & 185 \\
Ruff Calidris pugnax & 1 & 216 \\
Little Auk Alle alle & 1 & 200 \\
Water Rail Rallus aquaticus & 1 & 125 \\
Goldcrest Regulus regulus & 1 & 6 \\
Common Starling Sturnus vulgaris & 1 & 130 \\
Common Blackbird Turdus merula & 8 & 88 \\
Redwing Turdus iliacus & 4 & 219 \\
\hline Total & 32 & \\
Average & &
\end{tabular}

